\title{
FRUIT RIPENING ASYNCHRONY IS RELATED TO VARIABLE SEED NUMBER IN AMELANCHIER AND VACCINIUM ${ }^{1}$
}

\author{
DAVID L. GORCHOV \\ Division of Biological Sciences, University of Michigan, Ann Arbor, Michigan 48 109-1048
}

\begin{abstract}
A B S T R A C T
Two vertebrate-dispersed woody plants, Vaccinium corymbosum and Amelanchier arborea, were studied in southeastern Michigan to determine the proximate causes of their within-plant fruit ripening asynchrony. Individual flowers were followed from opening ( $A$. arborea) or fruit initiation ( $V$. corymbosum) to fruit ripening. Fifty-nine to $100 \%$ of the variance in fruit-ripening dates within $V$. corymbosum plants was due to variance in the development time; little was due to variance in initiation dates or covariance between these two terms. Similarly, $98 \%$ of the variance in fruit-ripening dates in $A$. arborea was due to variance in the number of days from flower opening to fruit ripening. Fruit developmental time in $V$. corymbosum and flower-fruit interval in $A$. arborea were significantly correlated with seed number: fruits with more seeds developed faster. I hypothesize that in both species ripening asynchrony is largely a consequence of variability in seed number.
\end{abstract}

ASYNCHRONY in the ripening of fleshy fruits on an individual plant occurs in many species with animal-dispersed seeds (Frankie, Baker and Opler, 1974; Thompson and Willson, 1979; Hilty, 1980; Opler, Frankie and Baker, 1980; Howe and Smallwood, 1982). Several recent hypotheses suggest this ripening asynchrony is an adaptation for increased reproductive success. According to one hypothesis, the increased duration of the fruit display resulting from ripening asynchrony may increase either the number and diversity of animals taking fruits (frugivores) (Smythe, 1970; McDonnell et al., 1984) or the diversity of weather conditions to which seeds are exposed following dispersal (Stapanian, 1982). A second hypothesis is that asynchronous ripening reduces the time ripe fruits remain on the plant before dispersal, exposed to predation and decay, when dispersers are not abundant. This scarcity of dispersers may be due either to seasonal changes in abundance (e.g., migration) (Thompson and Willson, 1979; Herrera, 1982) or to specialization by the plant for dispersal by frugivores

\footnotetext{
${ }^{\mathrm{I}}$ Received for publication 9 April 1985; revision accepted 17 July 1985 .

I thank the Museum of Zoology, University of Michigan, for permission to use the Edwin S. George Reserve and for an ESGR scholarship. I received additional support from Rackham Block Grants from the University of Michigan and a National Science Foundation Graduate Fellowship. C. Bartley, J. Dudley, S. Fogle, and S. Waldman helped with field work and/or data compilation. J. Fry and G. Estabrook helped refine the variance-partitioning model. A. Stephenson, D. Levey, S. Hermann, and S. Vander Kloet kindly shared unpublished data. J. Bronstein, G. Estabrook, D. Goldberg, and B. Rathcke provided valuable comments on earlier drafts of this manuscript.
}

with low population density (i.e., specialist or obligate frugivores, McKey, 1975; Howe and Estabrook, 1977). Third, ripening asynchrony may reduce the number of ripe fruits available at any one time, and this may decrease the time a frugivore forages on the plant, therefore increasing the proportion of ingested seeds dispersed away from the parent. A fourth hypothesis applies to species in which partially ripe fruits have colors distinct from ripe fruits; in these species asynchronous ripening may enhance the attractiveness of the fruit display by increasing the time it is bicolored (Stiles, 1982; Willson and Thompson, 1982). Finally, for species with indeterminate flowering (e.g., Phytolacca americana, McDonnell et al., 1984), asynchronous fruiting may enable a plant to more effectively exploit a growing season with an unpredictable termination.

While the ultimate (evolutionary) cause of within-plant ripening asynchrony has received much attention but remains unresolved, the proximate (mechanistic) cause of this phenomenon has received little attention to date. In this paper I present data bearing on three proximate mechanisms that could cause ripening asynchrony: asynchrony in flowering or fruit initiation, variability among fruits in the time from initiation to ripening (developmental time), and correlation between fruit initiation date and developmental time (i.e., early initiated fruits develop faster than later initiated fruits). Variability in fruit developmental time in turn might be due to characteristics of the fruits themselves, for example, the number of seeds in the fruit.

In this paper I present a model that uses 
TABLE 1. Partitioning of the variance in ripening date for fruits on five Vaccinium corymbosum plants and one Amelanchier arborea. See Methods for variance partitioning model. Var $=$ variance, $C o v=$ covariance, $R=$ ripening date, $I=$ fruit initiation date, $D=$ developmental time. Units for var and cov values are days ${ }^{2}$. For A. arborea, flower opening and flower-fruit interval were used in place of fruit initiation and developmental time

\begin{tabular}{|c|c|c|c|c|c|c|c|}
\hline Species & Plant no. & Fruits & $\operatorname{Var}(R)$ & $\operatorname{Var}(\mathbf{l})$ & $\operatorname{Var}(D)$ & $\operatorname{Cov}(I, D)$ & $\begin{array}{c}\text { Correlation } \\
\text { coefficient }(1, D)\end{array}$ \\
\hline \multirow[t]{5}{*}{ V. corymbosum } & 7 & 35 & 36.42 & 10.23 & 21.50 & 2.34 & .16 \\
\hline & 8 & 57 & 137.50 & 6.57 & 124.59 & 3.17 & .11 \\
\hline & 9 & 32 & 85.79 & 15.29 & 86.67 & -8.08 & -.22 \\
\hline & 11 & 33 & 146.61 & 19.28 & 133.68 & -3.17 & -.06 \\
\hline & 12 & 29 & 126.88 & 16.46 & 91.16 & 9.63 & .25 \\
\hline A. arborea & B-8 & 61 & 33.50 & 0.96 & 32.67 & -0.06 & .01 \\
\hline
\end{tabular}

variance-partitioning to quantify the contribution of flowering phenology, fruit developmental time, and the interaction between these factors, to ripening asynchrony. This model is applied to individuals of two species: Vaccinium corymbosum L. (Ericaceae), highbush blueberry, and Amelanchier arborea (Michx.f.) Fern. (Rosaceae), downy serviceberry. Both have fleshy fruits eaten by birds and mammals, many of which disperse seeds, and fruit-ripening phenologies that are more asynchronous than their flowering phenologies. Both also have a variable number of seeds per fruit, and I measure the amount of the variance in developmental time or ripening date explained by variance in seed number.

MATERIALS AND METHODS $-V$. corymbosum was studied in 1983 and $A$. arborea in 1984 at the E. S. George Reserve, Livingston Co., MI. Five $V$. corymbosum plants were selected for recording phenological patterns and fruit characteristics. One branch or a few adjacent branches on a single stem were selected on each plant before flowering began, and all flowers/ fruits were observed every 2 days during fruit initiation and ripening. The date of initiation was estimated as the date of the abscission of the corolla from the calyx. Fruits were considered ripe and were collected when they turned blue. They were weighed within $1 \mathrm{hr}$ of collection and refrigerated. Seeds were removed and counted within $2 \mathrm{wk}$ and scored as large $(\geq 1 \mathrm{~mm})$ or small.

Phenological data for individual flowers from opening to abscission or fruit ripening were obtained from one $A$. arborea plant for use in the variance-partitioning model. Comparative data on flowering and ripening phenologies were obtained from 10 other $A$. arborea plants, and data relating ripening date to seed number were obtained from an additional three plants.

On the $A$. arborea plant used to follow flowers from opening to ripening, 100 inflores- cences were checked daily and the date each flower $(N=562)$ opened (stigma first visible through petals) was recorded. After all flowers were open, they were observed weekly to determine which remained on the plant. The "ripening date" of each fruit $(N=61)$ was the first date it was observed to be red. Fruits that were removed by animals before turning red were assigned ripening dates based on my observation that fruits generally remain 1 day each in the "preripe" (loss of green color and swollen) and "pink" stages before turning red. Ripening date was designated as 1 day after a fruit turned pink or 2 days after it was preripe. Fruits that fell or were removed while still green were not assigned ripening dates.

On each of 10 other $A$. arborea plants, 10 inflorescences were randomly chosen and the date each flower on these inflorescences (51103 flowers per plant) opened was determined by daily observation. Starting shortly before ripening commenced, fruits on these inflorescences and others chosen randomly to total 100 per plant were checked every 2 days and their condition was recorded. Ripening dates were determined as above.

Fruit ripening dates, weights, and seed counts were obtained from three other $A$. arborea individuals. On each plant fruits on one branch or a few adjacent branches were checked every 2 days during the ripening period. Fruits were collected when they first turned either pink or red, then weighed and stored as for $V$. corymbosum. Seeds were scored as either filled or aborted based on inspection: plump seeds were considered filled, while flat or tiny $(<2 \mathrm{~mm})$ seeds were scored as aborted (when in doubt, I cut the seed and checked for the presence of white cotyledon filling the seed coat).

The variance in ripening date of fruits on each $V$. corymbosum plant was partitioned into three components: 1) variance in fruit initiation date, 2) variance in fruit developmental time, and 3) covariance between these factors. 
TABLE 2. Length of flower opening and fruit-ripening periods in all 11 Amelanchier arborea plants in 1984. Periods were calculataed as the minimum number of days that included at least $95 \%$ of the flower opening or fruit-ripening events on randomly chosen inflorescences

\begin{tabular}{ccc}
\hline \hline No. of plants & $\begin{array}{c}\text { Flower opening } \\
\text { (days) }\end{array}$ & $\begin{array}{c}\text { Fruit ripening } \\
\text { (days) }\end{array}$ \\
\hline 5 & 4 & $21-33$ \\
4 & 5 & $17-25$ \\
2 & 6 & $21-22$ \\
\hline
\end{tabular}

This variance partitioning was based on the following model. For each fruit, the ripening date, $R$, can be described by:

$$
\mathrm{R}=\mathrm{I}+\mathrm{D}
$$

where $I=$ the date of fruit initiation and $D=$ the developmental time of the fruit. The variance in date of ripening (ripening asynchrony) for the fruits on a plant is therefore:

$$
\operatorname{var}(R)=\operatorname{var}(I)+\operatorname{var}(D)+2 \operatorname{cov}(I, D)
$$

where $\operatorname{var}=$ variance and $\operatorname{cov}=$ covariance. The magnitude of the terms on the right side of Eq. 2 can be compared to quantify the contribution of each to the total ripening asynchrony.

This model was modified slightly to partition the variance in ripening date of fruits on the $A$. arborea plant for which I had followed individual flowers from opening to fruit ripening. Because I did not determine the initiation date of each fruit, I used flower opening date in its place and flower-fruit interval (number of days from flower opening to fruit ripening) in place of fruit developmental time. Fruit initiation (based on stigma browning) occurred a mean of $6.5(\mathrm{SD}=1.5)$ days after flower opening on a sample of 79 flowers on 11 plants.

RESULTS-For $V$. corymbosum, variance in fruit initiation date acounted for only $5 \%-28 \%$ of the within-plant variance in date of fruit ripening on the five study plants. Most (59\%$100 \%$ ) of the variance in fruit ripening date was due to variation in fruit developmental time (ripening date minus initiation date). Initiation date and developmental time of fruits were uncorrelated in each of the plants: early initiated fruits did not develop faster or slower than later initiated fruits (Table 1).

$A$. arborea flowered very synchronously: $95 \%$ of the flowers on each of 11 trees opened in only $4-6(\bar{x}=4.7 \pm 0.8 \mathrm{SD})$ days. Fruit ripening was much less synchronous: these same trees
TABLE 3. Correlations of large seed number with developmental time, weight, and weight/large seed for fruits on five Vaccinium corymbosum plants

\begin{tabular}{ccccc}
\hline \hline & & \multicolumn{2}{c}{$\begin{array}{c}\text { Correlation coefficient between } \\
\text { large seed number and:" }\end{array}$} \\
\cline { 3 - 5 } $\begin{array}{c}\text { Plant } \\
\text { no. }\end{array}$ & $\begin{array}{c}\text { Fruits } \\
\text { in } \\
\text { sample }\end{array}$ & $\begin{array}{c}\text { Developmental } \\
\text { time }\end{array}$ & Fruit wt & $\begin{array}{c}\text { Fruit wt } \\
\text { - Large } \\
\text { seed no. }\end{array}$ \\
\hline 7 & 37 & $-.62^{* * \mathrm{c}}$ & $.43^{* *}$ & -.72 \\
8 & 57 & $-.43^{* *}$ & $.44^{* *}$ & $-.64^{\mathrm{d}}$ \\
9 & 32 & $-.42^{*}$ & $.39^{* *}$ & -.69 \\
11 & 33 & $-.64^{* *}$ & $.62^{* *}$ & -.75 \\
12 & 29 & $-.70^{* *}$ & $.51^{* *}$ & $-.64^{\mathrm{c}}$ \\
Total & 188 & $-.46^{* * f}$ & $.46^{* *}$ & $-.66^{\mathrm{f}}$ \\
\hline
\end{tabular}

${ }^{*} * P<.05,{ }^{* *} P<.01$.

${ }^{b}$ Sig. tests not appropriate because variables are not independent.

c $N=35$.

d $N=56$

c $N=28$.

${ }^{\mathrm{r}} N=186$.

required $17-33(\bar{x}=23 \pm 5 \mathrm{SD})$ days to ripen $95 \%$ of their fruits (Table 2). Variance in the flower-fruit interval was by far the most important component of fruit-ripening asynchrony, accounting for $98 \%$ of the variance in fruit ripening on the study plant. Variance in flowering date made a negligible contribution to ripening asynchrony, and flowering date was uncorrelated with flower-fruit interval (Table $1)$.

The developmental time of $V$. corymbosum fruits was significantly correlated with the number of large seeds in the fruit: Fruits with more seeds developed faster. (There was an overall mean of $9.4(\mathrm{SD}=6.4)$ large seeds per fruit.) Seed number explains $18 \%-49 \%$ of the variance in developmental time of fruits on a plant (based on $r^{2}$ ) (Table 3). The ripening date of $A$. arborea fruits was highly negatively correlated with the number of filled seeds (Table 4). Nearly all fruits had 10 seeds in total, but the number of these that were filled ranged from 0 to $10(\bar{x}=3.8 \pm 2.2 \mathrm{SD})$. The amount of variance in ripening date $\left(r^{2}\right)$ explained by seed number was $42 \%-53 \%$.

In both species the weight of the fruit was positively correlated with seed number (Tables $3,4)$. Although fruits with more seeds weighed more, the increase in weight was not proportional to the increase in seed number. Therefore, the "per seed" fruit weight (i.e., fruit weight/seed number) was negatively correlated with seed number (Tables 3, 4).

Discussion-Within-plant fruit ripening asynchrony is not due to flowering asynchrony in $V$. corymbosum or $A$. arborea. While flow- 
TABLE 4. Correlation of filled seed number with ripening date, weight, and weight/filled seed for fruits on three Amelanchier arborea trees

\begin{tabular}{rcccc}
\hline & & \multicolumn{2}{c}{$\begin{array}{c}\text { Correlation coefficient between } \\
\text { filled seed number and }{ }^{*}\end{array}$} \\
\cline { 3 - 5 } $\begin{array}{c}\text { Plant } \\
\text { no. }\end{array}$ & $\begin{array}{c}\text { Fruits } \\
\text { in } \\
\text { sample }\end{array}$ & Ripening date & Fruit wt & $\begin{array}{c}\text { Fruit wt } \\
\div \text { Filled } \\
\text { seed no. }\end{array}$ \\
\hline 6 & 66 & $-.72^{* *}$ & $.36^{* *}$ & -.74 \\
18 & 37 & $-.73^{* *}$ & $.83^{* *}$ & -.50 \\
34 & 17 & $-.65^{* *}$ & $.61^{* *}$ & -.84 \\
\hline
\end{tabular}

a ** $P<.01$.

${ }^{b}$ Sig. test not appropriate because variable are not independent.

ering and fruit initiation are fairly asynchronous in $V$. corymbosum, variance in fruit initiation date accounts for only a small portion of the variance in fruit-ripening date. Variance in fruit developmental time is the major contributor to ripening asynchrony, and this developmental time is independent of fruit initiation date.

In $A$. arborea, flowering is much more synchronous than fruit ripening and the variance in date of flower opening contributes negligibly to the variance in date of ripening of fruits derived from those flowers. In addition, early opening flowers show no tendency to develop into ripe fruits faster than later flowers.

What accounts for the variance in developmental time in $V$. corymbosum and flowerfruit interval in $A$. arborea? In both species variance in seed number per fruit may be an important factor. The correlation between seed number and developmental time among fruits within individual plants has not been previously reported, but fruits from early pickings are known to average more seeds per fruit than later pickings of the same plants in both $V$. corymbosum (Dorr and Martin, 1966; Brewer and Dobson, 1969) and $V$. angustifolium (Aalders and Hall, 1961). Similarly, among groups of Pearson tomatoes there is a significant positive correlation between average seed number and average maturity index (based on a three-point scale) at harvest (Dempsey and Boynton, 1965); in zucchini, fruits with more seeds have higher growth rates and achieve final size earlier (A. G. Stephenson, pers. comm.).

The mechanism for the more rapid development and earlier ripening of fruits with more seeds may be the stronger physiological sink produced by a fruit with more developing seeds. In support of this hypothesis, developing seeds are known to produce auxins and giberellins in a variety of species, and the resultant hormone gradient has been shown to regulate the growth of the fruit (Crane, 1964; Nitsch, 1970; Goodwin, 1978; Wareing and Phillips, 1978, p. 123). Seed number is known to affect fruit size in many crop plants (Crane, 1964, p. 303; Wareing and Phillips, 1978, p. 123), including V. corymbosum (Eaton, 1967; Brewer and Dobson, 1969).

In V. corymbosum and A. arborea, seed number is significantly correlated not only with fruit size, but also with fruit maturation date. Perhaps it is because of their earlier maturation that fruits with more seeds have lower fruit weight per seed than fruits with fewer seeds. A dependence of ripening time on seed number may be an adaptation to conserve fruit size, minimize the energetic costs of producing many-seeded fruits, or achieve asynchrony in ripening. Alternatively, it may be the simplest outcome of the source-sink relationship.

What causes the variability in seed number in $A$. arborea and $V$. corymbosum? Variability in the amount of outcrossed pollen received by flowers may be important. The number of seeds per $V$. corymbosum fruit is greater in fruits from hand-outcrossed than from handselfed flowers and in plants in enclosures with large numbers of bees (Dorr and Martin, 1966; Brewer, Dobson and Nelson, 1969; van der Kloet, pers. comm.). There is little to no selfcompatibility in $A$. arborea; Robinson (1982) found this species to be self-incompatible, and I found fruit set on hand-selfed or bagged flowers (2\% matured) to be much lower than that on hand-outcrossed flowers $(21 \%)$. This partial or complete self-incompatibility suggests that seed set per fruit might also be dependent on cross-pollination. Abortion of developing seeds (Stephenson, 1981) could alternatively account for variability in seed number.

Individuals of other species ripen fruits asynchronously without any variability in seed number. Two asynchronous ripeners I have studied have invariable seed number: Gaylussacia baccata (10 seeds) and Prunus serotina (1 seed). Ripening asynchrony in two neotropical shrubs, Hamelia patens and Psychotria pilosa is at least partly due to the presence of ripe fruits delaying the ripening of other fruits on the same infructescence (D. Levey and S. Hermann, unpubl. data).

In plants of both $V$. corymbosum and $A$. arborea, most of the ripening asynchrony (variance in ripening date of fruits) is attributable to variance in fruit developmental time. Fruit developmental time, in turn, is highly correlated with seed number. However, the ultimate (evolutionary) cause of ripening asynchrony in these species remains untested. It is possible that ripening asynchrony per se is not adaptive 
in these species, but rather is a consequence of variability in seed number per fruit. This variability may be either adaptive for some other reason, or not under the control of the parent plant.

\section{LITERATURE CITED}

Aalders, L. E., ANd I. V. Hall. 1961. Pollen incompatibility and fruit set in lowbush blueberries. Can. J. Genet. Cytol. 3: 300-307.

Brewer, J. W., and R. C. Dobson. 1969. Seed count an $\mathfrak{d}$ berry size in relation to pollinator level and harvest date for the highbush blueberry, Vaccinium corymbosum. J. Econ. Entomol. 62: 1353-1356.

,-- AND J. W. Nelson. 1969. Effects of increased pollinator levels on production of the highbush blueberry, Vaccinium corymbosum. J. Econ. Entomol. 62: 815-818.

Crane, J. C. 1964. Growth substances in fruit setting and development. Annu. Rev. Plant Physiol. 15:303326.

Dempsey, W. H., And J. E. Boynton. 1965. Effect of seed number on tomato fruit size and maturity. Proc. Amer. Soc. Hort. Sci. 86: 575-581.

Dorr, J., AND E. C. MARTin. 1966. Pollination studies on the highbush blueberry, Vaccinium corymbosum L. Q. Bull. Mich. State Univ. Agric. Exp. Stn. 48: 437448.

EATON, G. W. 1967. The relationship between seed number and berry weight in open-pollinated highbush blueberry. HortScience 2: 14-15.

Frankie, G. W., H. G. Baker, AND P. A. Opler. 1974. Comparative phenological studies of trees in tropical wet and dry forests in the lowlands of Costa Rica. J. Ecol. 62: 881-919.

Goodwin, P. B. 1978. Phytohormones and fruit growth. In D. S. Letham, P. B. Goodwin, and T. J. V. Higgins [eds.], Phytohormones and related compounds-a comprehensive treatise, Vol. II, pp. 175-214. Elsevier, North-Holland Biomedical Press, New York.

Herrera, C. M. 1982. Defense of ripe fruit from pests: its significance in relation to plant-disperser interactions. Amer. Nat. 120: 218-241.

HILTY, S. L. 1980. Flowering and fruiting periodicity in a premontane rain forest in Pacific Colombia. Biotropica 12: 292-306.
Howe, H. F., AND G. F. Estabrook. 1977. On intraspecific competition for avian dispersers in tropical trees. Amer. Nat. 111:817-832.

- AND J. SMALlwoOd. 1982. Ecology of seed dispersal. Annu. Rev. Ecol. Syst. 13: 201-228.

MCDonnell, M. J., E. W. Stiles, G. P. Cheplick, AND J. J. ARmesto. 1984. Bird-dispersal of Phytolacca americana $\mathrm{L}$. and the influence of fruit removal on subsequent fruit development. Amer. J. Bot. 71: 895901.

MCKeY, D. 1975. The ecology of coevolved seed dispersal systems. In L. E. Gilbert and P. H. Raven [eds.], Coevolution of animals and plants, pp. 159-191. University of Texas Press, Austin.

NitsCH, J. P. 1970. Hormonal factors in growth and development. In A. C. Hulme [ed.], The biochemistry of fruits and their products, Vol. 1, pp. 428-472. Academic Press, New York.

Opler, P. A., G. W. Frankie, ANd H. G. Baker. 1980 Comparative phenological studies of treelet and shrub species in tropical wet and dry forests in the lowlands of Costa Rica. J. Ecol. 68: 167-188.

Robinson, W. A. 1982. Experimental taxonomy in the genus Amelanchier II: do the taxa in the genus Amelanchier form an agamic complex? Rhodora 84: 85100.

SMYThe, N. 1970. Neotropical fruiting seasons and seed dispersal. Amer. Nat. 104: 25-35.

Stapanian, M. A. 1982 . Evolution of fruiting strategies among fleshy-fruited plant species of eastern Kansas. Ecology 63: 1422-1431.

StePhenson, A. G. 1981. Flower and fruit abortion: proximate causes and ultimate functions. Annu. Rev. Ecol. Syst. 12: 253-279.

Stiles, E. W. 1982. Fruit flags: two hypotheses. Amer. Nat. 120: 500-509.

Thompson, J. N., AND M. F. Willson. 1979. Evolution of temperate fruit/bird interactions: phenological strategies. Evolution 33: 973-982.

Wareing, P. F., AND I. D. J. Phillips. 1978. Control of growth and differentiation in plants, 2nd ed. Pergamon Press, Oxford, New York.

Willson, M. F., AND J. N. Thompson. 1982. Phenology and ecology of color in bird-dispersed fruits, or why some fruits are red when they are "green." Can. J. Bot. 60 : 701-713. 